\title{
College Students' Internet Anomie and Intervention Countermeasures
}

\author{
Tong Liu ${ }^{1, *}$ \\ ${ }^{1}$ School of Teacher Education, Jiangsu University, Zhenjiang, China \\ *Corresponding author. Email: 664008548@qq.com
}

\begin{abstract}
With the vigorous development of higher education, the anomie behavior of college students has gradually attracted social attention. The current anomie behavior of Chinese college students is mainly concentrated in three aspects: anomie of network behavior, anomie of academic behavior, and anomie of job seeking process. The most prominent problem is the anomie of network behavior, which mainly includes promiscuous netizens, plagiarism, and even the Internet Crime, etc. There are many reasons for anomie, such as the low social cost of anomie, the lack of targeted education in schools, and the poor self-control of college students. Therefore, it is imminent to carry out the intervention of college students' Internet anomie. Intervention of college students' anomie behavior should be completed by the society, universities and students themselves. The society should improve laws and regulations and create a good environment; colleges and universities should make good use of multiple channels to guide student behavior; college students themselves should cultivate network cognition and improve self-intervention capabilities.
\end{abstract}

Keywords: college students, Internet anomie, intervention countermeasures

\section{INTRODUCTION}

Anomie is a sociological concept. "Anomie, in a narrow sense, refers to violations of ethics and conduct that violates rules and regulations. In a broad sense, it includes violations of ideology and morals, ethics, rules and regulations, as well as violations of laws and even criminal acts." (Wang Jitao, 2004) The anomie behavior in this article mainly refers to the behavior of college students who violates or deviates from behavior norms or social expectations, which has a negative impact and is negatively evaluated by others. With the advent of the era of big data, China is facing the impact and challenges of globalization and informatization. While online behavior has become a new way of social behavior for people, online life has also impacted the lives of contemporary college students. The problem is inevitably getting worse. (Wen Lan, 2017) At present, the anomie behaviors of Chinese college students are mainly concentrated in three aspects: the anomie of network behavior, the anomie of academic behavior and the anomie of job seeking process. Among them, the anomie of network behavior is the most serious. According to the 44th "Statistical Report on the Development of the Internet in China", as of June 2019, the scale of Internet users in China reached 854 million, of which 10-39 years old Internet users accounted for $65.1 \%$ of the total, and 20-29 years old Internet users accounted for the highest proportion, reaching $24.6 \%$.
As a special group of Internet users in this age group, college students are closely related to the Internet in all aspects of their lives and studies. While the Internet facilitates their study and life, it also triggers promiscuous netizens, plagiarism, and even cybercrime. This kind of anomie behavior has a bad impact on the physical and mental growth of college students, so college students' anomie behavior on the Internet should be highly valued.

\section{THE MANIFESTATION OF COLLEGE STUDENTS' INTERNET ANOMIE}

The Internet is an essential part of the study and life of college students. The so-called network anomie behavior of college students refers to all irrational behaviors that violate the morals and crimes that college students show in the process of using the Internet. (Zhang Jinsheng, 2012) This article analyzes the main manifestations of college students' behavioral anomalies in the network based on the behavioral stages of college students' use of the network, mainly from the three modules of "contacting the network", "selecting content" and "participating in using".

\section{A. Anomie in contact with the network}

The Internet has attracted countless young students for its advantages such as large amount of information, wide coverage, and fast transmission speed. College 
students' contact with the Internet is at least from junior high school. Classmates with conditions even go online every day. It is the online games that most easily make students feel dependent on the Internet. Some college students spend their time, money, and energy on online games and online dating, while in the learning life they are sluggish, resisting communication with others, and even obscuring their own moral cognition.

\section{B. Anomie in selecting web content}

The openness of the network and the interactive nature of the operation make everyone can speak freely on the Internet, and many "net celebrities" with millions and millions of fans are even more influential and powerful than governments. In such a network environment, many college students who are not deeply involved in the world will receive information incorrectly, which will lead to anomie behavior. Contemporary college students rely heavily on Weibo, WeChat, twitter and other social software. Some students even like to follow up and reprint comments on topics of interest. Only a few students will go to authoritative websites or newspapers to verify what they browse to. This has caused some college students to use their disseminated false or even reactionary information without opinion. Such bad information can make students deceived, but it will affect campus safety and even disrupt social harmony and stability.

\section{Anomie in using the network}

One of the prominent features of the network is concealment and virtuality. This makes college students feel free and unrestrained in the process of using the network, which further weakens the sense of moral responsibility and leads to the occurrence of network anomie. Some college students, including myself, are not quite the same as real people in my life when chatting with netizens. The Internet will add our selfconfidence invisibly. In addition, there are all kinds of materials on the Internet. Students can directly obtain a lot of resources from the Internet when completing assignments, dissertations and survey reports. This has also caused some students to plagiarize. There are even students who use their knowledge and skills to violate the privacy of others, or to make illegal profits.

\section{ATTRIBUTION ANALYSIS OF COLLEGE STUDENTS' INTERNET ANOMIE}

The attribution of college students' Internet anomie can be analyzed from three aspects: macro, meso and micro.

\section{A. Macro reasons}

The imperfect social credit system has reduced the cost of undergraduate behaviors. China currently does not have a complete credit system. Social laws and regulations lag behind. The supervision of government is insufficient. The irresponsible remarks made by college students on the Internet are once criticized for education as long as they do not violate the law. With the rapid development of the Internet today, the establishment and improvement of China's Internet laws and regulations is still relatively lagging behind, and there are large "blind spots". As the network's scope of influence continues to expand, the speed continues to increase, more and more problems arise. It takes time to formulate and revise relevant laws, and laws usually formulate corresponding clauses for related issues after problems arise. This has led to the "unreliable" of many online behaviors. In addition, due to problems such as infrequent equipment updates and uneven funding support by regulatory authorities, comprehensive monitoring is difficult to achieve. There is still a certain gap between China's network technology and western countries. There are hidden dangers in network security, which facilitates some people to explore legal gaps. It is difficult for young college students to guide and supervise the network behavior in such an environment, which led to the occurrence of anomie. Social control theory believes that all human activities must be carried out under a certain social relationship. This social relationship is a manifestation of social order. It can connect and organize individual people and unify their thoughts and behaviors. All social activities of humans meet the needs of social development. Only by formulating clear legal policies, can we more effectively restrict and punish the behaviors of college students' Internet anomie.

\section{B. Meso reasons}

Universities and colleges lack effective interventions. In recent years, major colleges have adopted relevant measures to intervene in students' online behaviors, and have also achieved certain results. But the network ideological and political education of various colleges still faces challenges. It is obviously not enough to rely solely on top-down education to guide efficiency. There are still many college students who do not understand the meaning of normative behavior. Intervention of network behavior is a systematic project, which can only be realized through the coordination and cooperation of various departments and units in colleges. The current educational countermeasures have the following two problems: First, the content of the behavioral standards of colleges and universities is not comprehensive and detailed. They are often in a lagging and passive state, and their actual operability is not strong. Second, punishment regulations are only as a means. But the most fundamental means is to strengthen prevention and education. Although each school has a manual that stipulates the students' various behaviors, it is unknown whether students have understood and mastered the 
manual. In addition, most colleges and universities in China have not yet offered related courses such as online ethics education. Existing online related courses also pay more attention to technical education rather than moral education. The lag in the construction of campus network culture is also an important cause of college students' Internet anomie.

\section{Micro reasons}

Affected by age and environment, college students cause some problems of their own. For example, some students like to pursue new things, but they are poor in self-discipline, easily addicted, and regret later. It is difficult to restrain themselves and leading to a vicious circle. In the face of a large amount of network information, lacking of judgment is very easy to be used by others, and become a pusher virtually. Generally speaking, the psychological motivations lead to anomie, including catharsis, bragging, interest, revenge, and so on. According to the available data, high employment pressure, weak competitiveness, and inconsistent personal expectations with reality can lead to nervousness and anxiety, while college students will become more dependent on the Internet in times of depression, frustration, and loneliness.

\section{INTERVENTION AND COUNTERMEASURES OF COLLEGE STUDENTS' INTERNET ANOMIE}

The impact of the Internet age on college students' network behavior and even ideological and political education is multifaceted and profound. Therefore, according to the characterization and cause analysis of college students' Internet anomie, some targeted intervention measures can be formulated.

\section{A. Macro level: improving laws and regulations and creaing a good environment}

Firstly, the government should formulate relevant laws and regulations. Absolute freedom does not exist in the world. Freedom must be bound and protected by corresponding laws and regulations, or freedom will gradually move towards its opposite. It is necessary to use the compulsory nature of the law to regulate the online behavior of college students, and to make the punishment of Internet anomie behavior lawful.

Secondly, it is to establish college student credit files based on the behavior of college students and incorporate them into their personal credit system. At present, college student files only record students' achievements, important awards, and disciplinary violations. Students' integrity is rarely recorded. This makes it difficult for students to learn about their daily behavior in school once they leave school. Therefore, college student integrity files should be used as an important supplement to student files, to record students' dishonesty, including network behavior, and more importantly, to record student corrections after school education. Only by strengthening the records of students' correction of errors, can they play a role in regulating student behavior through integrity files.

Thirdly, it needs to purify the network environment and create a good and comfortable social environment. It is precisely because college students are at an immature stage of life that they are susceptible to bad influences and blindly follow the trend, resulting in endless anomie behaviors. The whole society should work together, especially the government and regulatory authorities, to keep up with the times, constantly improve relevant laws and regulations and strengthen supervision.

\section{B. Meso level: making good use of multiple channels to guide student behavior}

Colleges and universities, as the main channels and main positions of network behavior intervention, should establish a management mechanism for college students 'network behavior intervention, follow the principle of "prevention-oriented and timely intervention", and cooperate with each other to effectively prevent and control university students' Internet anomie. On the one hand, students' behavioral standards can be improved according to the objective conditions of various disciplines and majors, the connotation of behavioral standards is elaborated from various aspects, and a manageable management system is formulated. On the other hand, courses such as network information knowledge, network laws and regulations, and network ethics can also be offered in different disciplines and specialties. In addition, we can also use the most popular online social tools among current students such as Weibo and WeChat to innovate the educational guidance model of behavioral norms. For example, through the official blog, WeChat public account to pass the norms of behavior to classmates equally and easily, or to take the Internet anomie behavior as the topic, let everyone fully express their opinions and participate in the discussion.

\section{Micro level: cultivating network cognition and improving self-intervention ability}

The main body of network anomie is students, so the most fundamental way is to improve students' selfintervention ability. On the one hand, young students in colleges and universities should be firm in their ideals, beliefs and values, and they must always restrain themselves. While establishing a sense of moral responsibility, it is necessary to strengthen moral selfdiscipline. In addition, college students should also improve network literacy and the ability to acquire, identify, and select network knowledge. On the other hand, college students should overcome their impetuous, nervous, and anxious mentality and stay 
down-to-earth. In addition, college students need to learn more about network ethics and strengthen their discernment ability. College students need to constantly reflect on themselves and adjust their bad tendencies in thinking and behavior in online activities. Furthermore, they should exercise self-discipline and develop conscious behavior. It is also necessary to make the standardized network behavior passive, including reasonable control of Internet surfing time and proper use of network content, so that students can internalize the standard network consciousness and externalize it.

\section{CONCLUSION}

Based on the analysis of college students' Internet anomie, this paper summarizes three reasons behind it: social reasons, school reasons, and student reasons. In addition, it also proposes corresponding intervention Countermeasures from these three perspectives. It is hoped that this article can provide some reference for the related research of college students' Internet anomie, and effectively reduce the incidence of college students' Internet anomie in the future.

\section{References}

[1] Wang Jitao,Analysis of Psychological Stress and Coping Strategies of Minor Anomie.Chinese Journal of Health Psychology. 2004.

[2] China Internet Network Information Center. 44th Statistical Report on Internet Development in China. http://www.cac.gov.cn/2019-08/30/c_1124938750.htm.

[3] Zhang Jingsheng, Construction of the Network Anomie Prevention Model for College Students.Journal of Theory and Practice of Education. 2012.

[4] Wen Lan, Research on College Students' Abnormal Behaviors in Internet and Guidance and Control Strategy. Science \& Technology Vision. 2017.

[5] Yang Zunwei. Types, Causes and Governance Strategies ofCollege Students' Network Anomie Behavior. Review of Higher Education. 2019.

[6] Hou Ming. A Study of College Students' Network Misconduct and Its Educational Path. 2017.

[7] Shen Zhenni. Research on the phenomenon and Countermeasures of network moral anomie of Contemporary College Students. 2018. 